\title{
Waiting to Exhale: Optimizing Noninvasive Synchrony in COPD?
}

Noninvasive ventilation (NIV) has become a widely used modality for many types of respiratory conditions. Some advantages of NIV include lower sedation requirement, preservation of cough and pulmonary clearance, and reduced frequency of ventilator-associated pneumonia. ${ }^{1}$ NIV has been used successfully in patients with cardiogenic pulmonary edema. ${ }^{2-4}$ It has been shown to decrease intubation duration and may improve the weaning results in chronic hypercapnic respiratory failure. ${ }^{5}$ It has been used successfully in acute hypoxemic respiratory failure, including community-acquired pneumonia and acute chest syndrome. ${ }^{6,7}$ In the case of COPD, it has become an accepted standard of care to treat exacerbations. Meta-analyses of randomized trials demonstrate that NIV can reduce the risk of death in COPD exacerbations. ${ }^{8-10}$ In a recent large retrospective cohort study, subjects with COPD treated with NIV at the time of hospitalization had lower in-patient mortality, shorter stay, and lower costs compared with those treated with invasive mechanical ventilation. ${ }^{11}$

To optimize the use of NIV, patient-ventilator synchrony must be considered. Pressure-support ventilation is a common mode of NIV used in COPD patients. ${ }^{12}$ Trigger and cycle are key components that determine the ability of the ventilator to synchronize with patient effort. Delayed cycling may lead to inspiratory effort continuing into the next breathing cycle, resulting in high intrinsic PEEP $\left(\mathrm{PEEP}_{\mathrm{i}}\right)$, which eventually leads to ineffective triggering. On the other hand, premature cycling may lead to double triggering, which would also result in an increase in PEEP $_{\mathrm{i}}$.

The NIV interface is also relevant. Unlike invasive mechanical ventilation, there are multiple interface choices. New interfaces have been created to try to improve on face mask-related adverse effects, such as discomfort, air leaks, and skin breakdown. An alternative to the traditional face mask is the helmet. The standard helmet has improved comfort and reduced skin breakdown compared with the

Dr Rettig has received research support from Draeger Medical.

Correspondence: Jordan S Rettig MD, Department of Anesthesiology, Perioperative, and Pain Medicine, Division of Critical Care Medicine, Boston Children's Hospital, 300 Longwood Avenue, Bader 634, Boston, MA 02115.

DOI: $10.4187 /$ respcare. 04573 face mask. ${ }^{13,14}$ However, the helmet is a more compliant interface, resulting in pressure dissipation and time lag between the initiation of the inspiratory effort and trigger. It has been reported that NIV delivered via helmet is less efficient than via face mask in reducing inspiratory effort

See the Original Study on Page 15

and worsens patient-ventilator synchrony. ${ }^{15-19}$ There has also been concern about $\mathrm{CO}_{2}$ rebreathing with inspired $\mathrm{P}_{\mathrm{CO}_{2}}$ being dictated by the amount of $\mathrm{CO}_{2}$ produced by the subject and the amount of fresh gas flow flushing the large dead space in the helmet.20,21 Higher flow in the helmet is required to overcome this, which may reduce patient comfort $^{22}$ The presence of rebreathing may create asynchrony by causing dyspnea and increased respiratory drive. ${ }^{23}$ In a recent study, the Helmet Next was compared with face mask and standard helmet. ${ }^{24}$ The Helmet Next interface design attempts to compensate for the pressure dissipation seen in the standard helmet. It was shown that the Helmet Next might have some advantages with respect to interaction and synchrony between subject and ventilator. ${ }^{24}$

In this issue of ResPiratory CARe, Moerer et al ${ }^{25}$ have published an article titled "Patient-ventilator interaction during noninvasive ventilation in simulated COPD." The authors used a lung model simulating NIV in a COPD patient to examine the effects of changing cycling criteria on patient-ventilator synchrony. Additionally, they examined this relationship using 2 different interfaces, face mask and helmet. The authors concluded that augmenting the cycling criterion above the typical default setting (20$30 \%$ peak inspiratory flow) improved patient-ventilator synchrony.

Specifically, they measured an asynchrony index, double-triggering index, expiratory trigger latency (defined as the end of inspiration effort until the end of pressure support, with positive values indicating delayed cycling and negative values indicating premature cycling), $\mathrm{PEEP}_{\mathrm{i}}$, and the additional expiratory pressure-time product $\left(\mathrm{PTP}_{\mathrm{E}}\right.$, which is defined as the pressure-time product above PEEP after the end of the inspiratory effort). They then examined the effects of low to medium cycling (20-30\% peak inspiratory flow) and medium to high cycling (50-60\% peak inspiratory flow). In the low to medium trial, they found that both the helmet and face mask showed reduction in 
expiratory trigger latency, $\mathrm{PTP}_{\mathrm{E}}$, and $\mathrm{PEEP}_{\mathrm{i}}$. In the medium to high cycling, they noted large reductions in expiratory trigger latency, but with that, significant reductions in tidal volume $\left(\mathrm{V}_{\mathrm{T}}\right)$ with both interfaces.

They then considered each cycle group separately and varying amounts of pressure support (PS) and breathing frequency. In the low cycling trial (10 and 20\% peak inspiratory flow), no double triggering occurred. They showed high expiratory trigger latency in high and low PS, and both interfaces showed high $\mathrm{PTP}_{\mathrm{E}}$ in high compared with low PS settings. The medium cycling trial (30, 40, and 50\% peak inspiratory flow) revealed no asynchrony if there was no leak and small asynchrony with a leak. Double triggering was observed in 50\% cycling. There was a significant decrease in expiratory trigger latency at all levels of support, with some values being close to zero. The $\mathrm{PTP}_{\mathrm{E}}$ was also lower at all PS settings as compared with the low cycling trial. They also noted that increasing cycling consistently decreased $\mathrm{V}_{\mathrm{T}}$. In the high cycling group (60 and 70\% peak inspiratory flow), they noted no asynchrony, but they did note double triggering in all scenarios with lower breathing frequency and none with higher breathing frequency. If there was a leak, double triggering was seen with high levels of PS. In all settings, expiratory trigger latency was lower than medium cycling. High cycling resulted in lower $\mathrm{PTP}_{\mathrm{E}}$ in all settings when using a helmet, whereas reductions were seen in low breathing frequency with a face mask, but increases in $\mathrm{PTP}_{\mathrm{E}}$ were noted at high breathing frequency. There was a $V_{T}$ reduction in all settings with both interfaces.

The authors included some further observations about differences between the face mask and helmet interface. They noted that expiratory trigger latency was more negative at high cycling in the helmet as compared with the face mask. This is probably due to the fact that the helmet is a more compliant interface, and the initial flow and pressure-time rise is affected by the properties of the helmet rather than the patient. It was also noted that much longer inspiration time was necessary to trigger a ventilator breath with the helmet. Therefore, triggering was less frequent with the helmet, occurring more frequently at lower PS, which corresponded to more negative expiratory trigger latency.

They also highlighted 2 scenarios in which increasing cycling may be particularly beneficial. They observed high PEEP $_{\mathrm{i}}$ in situations where high breathing frequency led to shortened expiration time and noted that this was improved by increasing cycling. They also noted that reduction in $\mathrm{PTP}_{\mathrm{E}}$ is necessary to ensure adequate exhalation and enhance patient comfort. $\mathrm{PTP}_{\mathrm{E}}$ was increased at higher levels of PS and was able to be decreased with higher cycling with both interfaces but was much lower with the helmet as compared with the face mask. This indicates that the helmet is superior at re- ducing expiratory pressure load. However, it may be that the lower PTP $_{\mathrm{E}}$ value may simply reflect a reduced PTP $_{\text {INSP }}$ and may come at the cost of less pressure unloading during inspiration.

The authors conclude that the best synchrony in a simulated COPD model ranged between 30 and $70 \%$ cycling. They appropriately recognize the limitations of answering this question with a model and suggest an individualized approach to setting cycling, instead of relying on default settings.

There are multiple elements to patient-ventilator asynchrony, including ineffective triggering, double triggering, autotriggering, and premature or delayed cycling. Moerer et $\mathrm{al}^{25}$ conclude that optimizing cycling does add theoretical benefit with improved synchrony and reduction in $\mathrm{PEEP}_{\mathrm{i}}$. The question is: By optimizing one parameter, are we trading one problem for another? This study is unable to determine how well patients would tolerate adjusting cycling. Increasing cycling may increase synchrony and decrease $\mathrm{PTP}_{\mathrm{E}}$ and $\mathrm{PEEP}_{\mathrm{i}}$, but it has also been shown to decrease $V_{T}$, which often results in increased discomfort and air hunger. This frequently results in tachypnea, which may then contribute to asynchrony and increased $\mathrm{PEEP}_{\mathrm{i}}$ due to decreased expiratory time.

Adjusting cycling improved synchrony in the helmet, which had historically been a problem with this interface. An interesting observation was that there was less double triggering with the helmet due to the increased compliance of the interface, which resulted in a longer time needed to trigger a breath. This had previously been perceived as a weakness of the helmet, namely that the more compliant interface was less efficient than the face mask in reducing inspiratory effort. Do we now have a new argument for the ventilation helmet in COPD? If there was less frequent double triggering, then premature cycling may not be as relevant to asynchrony and increased PEEP $_{\mathrm{i}}$. In this study, it was also noted that there might be potentially enhanced expiratory unloading. Is it better to use an interface that is unlikely to double-trigger so that we can use higher cycling to augment synchrony and more effective exhalation in COPD patients? We would have to once again consider patient comfort. The helmet would probably not provide optimized inspiratory unloading, and the delay in trigger coupled with lower tidal volumes on higher cycling would probably result in discomfort.

Bench studies remain an important way to elucidate physiology. However, NIV poses issues that reach beyond a simple understanding of physiology. Unlike invasively ventilated patients, patients using NIV are deliberately kept awake with minimal sedation. There are a variety of interface options. It is logical to conclude that better synchrony results in more comfort. However, some maneuvers to improve synchrony may result in an uncomfortable 


\section{NIV SYNCHRONY IN COPD}

pattern of breathing for the patient. In an effort to improve synchrony based on physiologic measures, we must not lose sight of patient comfort. Future investigation into the relationship between asynchrony and NIV optimization should be conducted in patients.

Jordan S Rettig MD

Department of Anesthesiology, Perioperative, and Pain Medicine

Division of Critical Care Medicine Boston Children's Hospital Harvard Medical School Boston, Massachusetts

\section{REFERENCES}

1. Sinuff T, Muscedere J, Cook DJ, Dodek PM, Anderson W, Keenan $\mathrm{SP}$, et al. Implementation of clinical practice guidelines for ventilator-associated pneumonia: a multicenter prospective study. Crit Care Med 2013;41(1):15-23.

2. Peter JV, Moran JL, Phillips-Hughes J, Graham P, Bersten AD. Effect of noninvasive positive pressure ventilation on mortality in patients with acute cardiogenic pulmonary oedema: a meta-analysis. Lancet 2006;367(9517):1155-1163.

3. Nava S, Carbone G, DiBattista N, Bellone A, Baiardi P, Consentini $\mathrm{R}$, et al. Noninvasive ventilation in cardiogenic pulmonary edema: a multicenter, randomized trial. Am J Respir Crit Care Med 2003; 168(12):1432-1437.

4. Gray A, Goodacre S, Newby DE, Masson M, Sampson F, Nicholl J, 3CPO Trialists. Noninvasive ventilation in acute cardiogenic pulmonary edema. N Engl J Med 2008;359(2):142-151.

5. Girault C, Bubenheim M, Abroug F, Diehl JL, Elatrous S, Beuret P, et al. Noninvasive ventilation and weaning in chronic hypercapnic respiratory failure patients: a randomized multicenter trial. Am J Respir Crit Care Med 2011;184(6):672-679.

6. Cosentini R, Brambilla AM, Aliberti S, Bignamini A, Nava S, Maffei A, et al. Helmet continuous positive airway pressure vs. oxygen therapy to improve oxygenation in community-acquired pneumonia: a randomized, controlled trial. Chest 2010;138(1):114-120.

7. Fartoukh M, Lefort Y, Habibi A, Bachir D, Galacteros F, Godeau B, et al. Early intermittent noninvasive ventilation for acute chest syndrome in adults with sickle cell disease: a pilot study. Intensive Care Med 2010;36(8):1355-1562.

8. Quon BS, Gan WQ, Sin DD. Contemporary management of acute exacerbations of COPD: a systematic review and meta analysis. Chest 2008;133(3):756-766.

9. National Institute for Health and Care Excellence. Chronic obstructive pulmonary disease (NICE clinical guideline 101): management of chronic obstructive pulmonary disease in adults in primary and secondary care (partial update). June 2010. http://guidance. nice.org.uk/cg101. Accessed October 21, 2015.

10. Lightowler JV, Wedzicha JA, Elliott MW, Ram FSF. Non-invasive positive pressure ventilation to treat respiratory failure resulting from exacerbations of chronic obstructive pulmonary disease: Cochrane systematic review and meta-analysis. BMJ 2003;326(7382):185.

11. Lindenauer PK, Stefan MS, Shieh MS, Pekow PS, Rothberg MB, Hill NS. Outcomes associated with invasive and noninvasive ventilation among patients hospitalized with exacerbations of chronic obstructive pulmonary disease. JAMA Intern Med 2014;174(12): 1982-1993.

12. Esteban A, Ferguson ND, Meade MO, Frutos-Vivar F, Apezteguia C, Brochard L, et al. Evolution of mechanical ventilation in response to clinical research. Am J Respir Crit Care Med 2008;177(2):170-177.

13. Antonelli M, Conti G, Pelosi P, Gregoretti C, Pennisi MA, Costa R, et al. Treatment of acute hypoxemic respiratory failure: noninvasive pressure support ventilation delivered by helmet: a pilot controlled trial. Crit Care Med 2002;30(3):602-608.

14. Antonelli M, Pennisi MA, Pelosi P, Gregoretti C, Squadrone V, Rocco M, et al. Noninvasive positive pressure ventilation using a helmet in patients with acute exacerbation of chronic obstructive pulmonary disease: a feasibility study. Anesthesiology 2004;100(1): 16-24.

15. Chiumello D, Pelosi P, Carlesso E, Severgnini P, Aspesi M, Gamberoni $\mathrm{C}$, et al. Noninvasive positive pressure ventilation delivered by helmet vs. standard face mask. Intensive Care Med 2003;29(10): 1671-1679.

16. Navalesi P, Costa R, Ceriana P, Carlucci A, Prinianakis G, Antonelli $\mathrm{M}$, et al. Non-invasive ventilation in chronic obstructive pulmonary disease patients: helmet versus facial mask. Intensive Care Med 2007;33(1):74-81.

17. Racca F, Appendini L, Gregoretti C, Stra E, Patessio A, Donner CF, Ranieri VM. Effectiveness of mask and helmet interfaces to deliver noninvasive ventilation in a human model of resistive breathing. J Appl Physiol 2005;99(4):1262-1271.

18. Vargas F, Thille A, Lyazidi A, Campo FR, Brochard L. Helmet with specific settings versus facemask for noninvasive ventilation. Crit Care Med 2009;37(6):1921-1928.

19. Navalesi P, Costa R, Ceriana P, Carlucci A, Prinianakis G, Antonelli $\mathrm{M}$, et al. Non-invasive ventilation in chronic obstructive pulmonary disease patients: helmet versus facial mask. Intensive Care Med 2007;33(1):74-81.

20. Taccone P, Hess D, Caironi P, Bigatello LM. Continuous positive airway pressure delivered with a "helmet": effects on carbon dioxide rebreathing. Crit Care Med 2004;32(10):2090-2096.

21. Mojoli F, Iotti GA, Gerletti M, Lucarini C, Braschi A. Carbon dioxide rebreathing during non-invasive ventilation delivered by helmet: a bench study. Intensive Care Med 2008;34(8):1454-1460.

22. Hess DR. Patient-ventilator interaction during noninvasive ventilation. Respir Care 2011;56(2):153-165; discussion 165-167.

23. Banzett RB, Lansing RW, Evans KC, Shea SA. Stimulus-response characteristics of $\mathrm{CO}_{2}$-induced air hunger in normal subjects. Respir Physiol 1996;103(1):19-31.

24. Vaschetto R, De Jong A, Conseil M, Galia F, Mahul M, Coisel Y, et al. Comparative evaluation of three interfaces for non-invasive ventilation: a randomized cross-over design physiologic study on healthy volunteers. Crit Care 2014;18(1):R2.

25. Moerer O, Harnisch L-O, Herrmann P, Zippel C, Quintel M. Patientventilator interaction during noninvasive ventilation in simulated COPD. Respir Care 2016;61(1):15-22. 